\title{
Clinician attitudes to pain and use of analgesia in cattle - Where are we 10- years on?
}

Remnant, J.G. ${ }^{1}$, Tremlett, A. ${ }^{2}$, Huxley, J.N. ${ }^{1}$ and Hudson, C.D. ${ }^{1}$

${ }^{1}$ School of Veterinary Medicine and Science, University of Nottingham, Sutton Bonington, Leicestershire LE12 5RD

${ }^{2}$ Goulburn Valley Equine Hospital, 905 Goulburn Valley Highway, Congupna,Victoria 3633, Australia John.remnant@nottingham.ac.uk 


\section{ABSTRACT}

Pain in cattle can arise though disease or injury or may result from veterinary or husbandry procedures. Controlling pain is important to safeguard animal welfare. Previous studies indicated that the use of analgesics in cattle has lagged behind use in companion animals. Over the last decade, more analgesic products have become available for use in cattle and there have been increased efforts to communicate the importance and benefits of analgesia. A questionnaire (based on that used in a similar study published in 2006) was sent to UK cattle practitioners asking them to score pain severity for several conditions of cattle and asking about their attitudes towards and use of analgesic medicines. A total of 242 surveys were returned. Male clinicians and those graduating before 1990 scored pain severity significantly lower and were significantly less likely to use nonsteroidal anti-inflammatory drugs (NSAIDs). Generally, use of NSAIDs was more common for conditions assigned higher pain scores. However, uptake of NSAID use was much lower for a number of routine procedures in calves than would be expected from the pain scores they were assigned. A need remains to increase use of analgesic products, especially NSAIDs in calves, in line with best practice recommendations.

\section{INTRODUCTION}

Painful conditions are frequently encountered in cattle, whether disease-associated or iatrogenic following veterinary or husbandry interventions. Pain responses have been demonstrated in cattle with various diseases including lameness (Whay and others 1997) and mastitis (Fitzpatrick and others 1998) and it is logical to assume that they occur for other common diseases and conditions. Pain has also been identified in cattle following veterinary or husbandry procedures including surgery (Walker and others 2011), castration (Robertson and others 1994) and disbudding (Graf and Senn 1999) and can arise as a result of inappropriate handling or management. Whilst prevention and avoidance is important, some degree of disease and the necessity of some husbandry procedures currently remains unavoidable. Reducing the pain caused by these diseases and procedures is an important aspect of maintaining farm animal welfare.

Numerous analgesic and anaesthetic products are available and licensed for use in farm animals, including non-steroidal anti-inflammatory drugs (NSAIDs) and local anaesthetics. The reduction in pain associated with using these products during routine husbandry procedures is well documented (Heinrich and others 2010; Heinrich and others 2009; Stafford and Mellor 2011; Stafford and others 2002), and there is increasing evidence to support the benefits in painful diseases as well, including lameness (Thomas and others 2015), mastitis (Fitzpatrick and others 2013) and metritis (Pohl and others 2016).

Cattle are naturally stoical animals, and whilst there are a number of pain assessment tools available for research, the use of analgesics in cattle relies heavily on the recognition and perception of pain by both producers and prescribing veterinarians. A previous large-scale survey evaluating the attitudes of UK cattle practitioners to pain and the use of analgesics identified that pain scores for different conditions varied markedly between individuals, with significant effects of gender and decade of graduation (Huxley and Whay 2006). The authors suggested that more work was needed to disseminate up-to-date knowledge to cattle practitioners. A similar approach in New Zealand (Laven and others 2009) revealed similar findings.

In the time since the previous survey, there has been an increase in the number of analgesics available, along with substantial efforts to promote the use of analgesics through knowledge 
exchange activities. The aim of this study was to assess whether perceptions of pain in cattle by cattle practitioners have changed in the intervening decade.

\section{MATERIALS AND METHODS}

Data was collected by questionnaire. The questionnaire was deliberately designed to be similar to that used by Huxley and Whay (2006) to allow comparisons to be made (see supplementary material). Paper copies of the questionnaire with a reply paid envelope were sent to 650 UK veterinary practices randomly selected from the mailing list of a pharmaceutical company (Boehringer Ingelheim). An electronic copy of the questionnaire was also created and distributed online using a web based system (SurveyMonkey Inc., California, USA, www.surveymonkey.com). Paper surveys were accompanied by a cover letter that also contained a link to the electronic survey and made it clear than multiple responses from a practice were allowed by either copying the paper version or by the electronic version. The survey was promoted with a letter in The Veterinary Record two weeks after being mailed out, emails promoting the survey were also circulated to members of the British Cattle Veterinary Association and around a network of independent farm animal practices (XLVets). These emails were sent approximately five and eight weeks after mailing the paper questionnaire. A copy of the paper version is included in the Supplementary Material. The questionnaire consisted of six parts:

1. Part one collected demographic information including gender, year and place of graduation, level of qualification and practice details.

2. Part two asked respondents to list the analgesic agents used for cattle in their practice.

3. Part three reviewed the use of analgesics in adult cattle, with factors affecting their use, followed by a list of conditions and procedures with questions regarding the respondent's use of analgesia for these conditions. Participants were also asked to score the expected pain severity (in the absence of any analgesia or anaesthesia) on a ten-point scale and what they would consider an acceptable cost for analgesia for each condition/procedure.

4. Part four was similar to part three but related to calves

5. Part five gathered information about the participant's opinions on analgesics by asking their agreement with a series of statements and whether their opinions had changed in the previous 5-10 years.

6. Part six asked about continuing education and where participants had gained their knowledge on pain in cattle.

Data from paper surveys was input into a spreadsheet (Microsoft Excel 2016; Microsoft Corp.) and merged with data from online respondents. Error checking and data audit was carried out at this stage. For pain score data, the distributions of scores across conditions and procedures were presented as boxplots. Pairwise associations between pain score assigned and various demographic factors were tested using Mann-Whitney $U$ tests for factors with two categories, and Kruskal-Wallis tests for factors with more than two categories. As there were substantial correlations within some of these demographic factors (for example, the higher proportion of female graduates in later years), a multivariable linear regression model was constructed with pain score as the outcome variable, using a respondent-level random effect to account for repeated scores within individuals. The model was built using forward selection, and visual assessment of distribution of residuals and influence plots was used to assess model fit.

Factors associated with use of analgesia were investigated in detail. The two main types of analgesia available (NSAIDs and local anaesthesia) were considered separately. Respondents were asked to estimate the proportion of cases in which they used each form of analgesia across a range of 
conditions and procedures. For NSAID use, the distribution of these responses was strongly bimodal, with respondents mostly giving values very close to either zero or $100 \%$ for a given condition. NSAID use was therefore recoded as a binary outcome (using $50 \%$ as the threshold percentage). This was compared graphically across conditions and procedures, and used as the outcome for a logistic regression model to investigate other factors associated with NSAID use. The model was built using forward selection, again using a respondent-level random effect to account for repeated responses within individual. Final parameter estimates were generated using a Markov Chain Monte Carlo procedure, and model fit checked using a Hosmer-Lemeshow test. Data analysis was carried out in $\mathrm{R}$ 3.2.5 (R Core Team 2013), with MLwiN 2.36 (Rasbash and others 2009) used for regression model building and parameter assessment.

\section{RESULTS}

\section{Demographic data}

A total of 102 paper questionnaires were returned, of which five were mostly incomplete. The response rate for the paper questionnaire was 16\% (102/650). A further 145 responses were received via the online survey, so a total of 242 questionnaires were analysed. It was not possible to calculate a response rate for the online survey because the extent of distribution was unknown. Where questions were omitted or filled in illegibly, those questions were not analysed for that respondent, but the remainder of the questionnaire was included in other analyses where possible. Demographic data is shown in Table 1.

Table 1: Demographic data for respondents to a survey investigating attitudes to pain and the use of analgesia in cattle

\begin{tabular}{|l|l|}
\hline Variable & $\begin{array}{l}\text { Percentage } \\
\text { of } \\
\text { respondents } \\
\text { (n=242) }\end{array}$ \\
\hline Gender & \\
\hline Male & $56 \%$ \\
\hline Female & $44 \%$ \\
\hline Year of graduation & \\
\hline before 1991 & $24 \%$ \\
\hline $1991-2000$ & $17 \%$ \\
\hline $2001-2005$ & $13 \%$ \\
\hline $2006-2010$ & $26 \%$ \\
\hline after 2010 & $20 \%$ \\
\hline School of graduation & \\
\hline Bristol & $19 \%$ \\
\hline Cambridge & $8 \%$ \\
\hline Edinburgh & $17 \%$ \\
\hline Glasgow & $16 \%$ \\
\hline Liverpool & $13 \%$ \\
\hline Nottingham & $6 \%$ \\
\hline RVC & $17 \%$ \\
\hline Other & $4 \%$ \\
\hline Practice position & \\
\hline & \\
\hline
\end{tabular}




\begin{tabular}{|l|l|}
\hline Employees & $61 \%$ \\
\hline Employers & $37 \%$ \\
\hline Additional qualifications & \\
\hline Certificate level & $11 \%$ \\
\hline Diploma-level & $7 \%$ \\
\hline $\begin{array}{l}\text { Proportion of time spent treating } \\
\text { cattle }\end{array}$ & $70 \%$ \\
\hline Median time & $40-90 \%$ \\
\hline $\begin{array}{l}\text { Lower and upper } \\
\text { quartile }\end{array}$ &
\end{tabular}

\section{Pain assessment}

The distributions of estimated pain score across conditions and procedures are shown in Figure 1. Ranked by median pain score, neck calluses and hock hair loss were considered the least painful (median score 3), whilst digit amputation was considered the most painful (median score 10). For most conditions, the inter-quartile range of scores covers 2-3 points on the scale, whilst most of the full range of scores was used for almost all conditions. For example, 21 out of the 27 conditions and procedures covered had some respondents scoring them at score 2 or 1 . Conversely, whilst hock hair loss was generally considered the joint least painful condition (based on median score), eight respondents scored this at 8 or higher.

For 12 of the 27 conditions and procedures, the median score had increased compared to a previous survey using the same questions and structure (Huxley and Whay 2006). The median score assigned to surgery to correct a left displaced abomasum was the only one to have decreased since the earlier work. In all of these cases, the change in median score was by one point.

Aggregating scores across all conditions, male respondents assigned lower scores (median score difference of one point, $p<0.01$ ). Initially, significant differences were also observed between year and school of graduation, pre-university background (all $p<0.01$ ) and attainment of a clinical postgraduate qualification $(p<0.05)$. Only gender of respondent and year of graduation remained in a multivariable linear model with pain score as the outcome, suggesting that the other pairwise associations were mostly confounded by gender and year of graduation. Female gender was associated with an increase of 0.36 in pain score. Year of graduation prior to 1990 was associated with a decrease of 0.48 in pain score compared to graduates since 2010 , but graduation between these years was not significantly different to either group.

\section{Attributing acceptable cost of analgesia}

Acceptable costs of analgesia given by respondents are shown in Table 2. In adults, higher costs were considered acceptable for the three surgical conditions, a similar pattern was observed in the conditions and procedures affecting calves. Surgical castration, disbudding and following dystocia were allocated the lowest acceptable cost (55-65\% of respondents considering less than $£ 2$ per case acceptable). Acceptable costs were also compared to estimated approximate costs of providing analgesia for each condition or procedure. For adult cattle, the cost of providing analgesia was considered acceptable where the respondent had selected a cost of $£ 10-20$ or above (as $£ 20$ would cover an NSAID treatment plus local anaesthetic treatment where appropriate). For calves, the cost of treatment was considered acceptable where a cost of $£ 0.01-£ 2$ or above was selected (on the same basis). The estimated cost of analgesia was below or within the respondents' acceptable range for a very high proportion of respondents across most conditions (for greater than $90 \%$ of 
respondents for caesarean section, surgical castration, digit amputation, calf disbudding, umbilical hernia surgery, joint ill and distal limb fracture). However, there were a small number of conditions where the estimated cost more commonly fell above the respondent's acceptable range (with $80 \%$ of respondents selecting an acceptable cost below the estimated true cost for adult dehorning, $72 \%$ for uveitis and $40 \%$ for treatment of a sole ulcer).

Table 2: Acceptable costs of analgesia for various procedures and conditions of adult cattle and calves given by respondents in a survey investigating attitudes to pain and the use of analgesia in cattle $(n=242)$

\begin{tabular}{|c|c|c|c|c|c|c|c|}
\hline & \multicolumn{7}{|l|}{ Adult } \\
\hline $\begin{array}{l}\text { Acceptable } \\
\text { cost }\end{array}$ & Sole ulcer & $\begin{array}{l}\text { Claw } \\
\text { amputation }\end{array}$ & Caesarean & Dystocia & De-horning & Uveitis & $\begin{array}{l}\text { LDA } \\
\text { surgery }\end{array}$ \\
\hline None & $7 \%$ & $0 \%$ & $0 \%$ & $1 \%$ & $3 \%$ & $17 \%$ & $1 \%$ \\
\hline$£ 0-10$ & $27 \%$ & $8 \%$ & $7 \%$ & $19 \%$ & $66 \%$ & $44 \%$ & $11 \%$ \\
\hline f10-20 & $33 \%$ & $40 \%$ & $29 \%$ & $42 \%$ & $16 \%$ & $19 \%$ & $33 \%$ \\
\hline f20-35 & $15 \%$ & $25 \%$ & $35 \%$ & $22 \%$ & $1 \%$ & $3 \%$ & $31 \%$ \\
\hline$>£ 35$ & $3 \%$ & $14 \%$ & $17 \%$ & $3 \%$ & $0 \%$ & $0 \%$ & $10 \%$ \\
\hline \multirow[t]{2}{*}{ no response } & $14 \%$ & $13 \%$ & $12 \%$ & $13 \%$ & $14 \%$ & $16 \%$ & $14 \%$ \\
\hline & \multicolumn{6}{|l|}{ Calf } & \\
\hline $\begin{array}{l}\text { Acceptable } \\
\text { cost }\end{array}$ & Castration & Joint ill & $\begin{array}{l}\text { Hernia } \\
\text { surgery }\end{array}$ & Disbudding & $\begin{array}{l}\text { Limb } \\
\text { fracture }\end{array}$ & Dystocia & \\
\hline None & $8 \%$ & $5 \%$ & $1 \%$ & $3 \%$ & $0 \%$ & $16 \%$ & \\
\hline$f 0-2$ & $35 \%$ & $10 \%$ & $5 \%$ & $48 \%$ & $5 \%$ & $27 \%$ & \\
\hline$f 2-5$ & $30 \%$ & $43 \%$ & $19 \%$ & $25 \%$ & $23 \%$ & $23 \%$ & \\
\hline f5-10 & $7 \%$ & $20 \%$ & $36 \%$ & $5 \%$ & $32 \%$ & $11 \%$ & \\
\hline$>£ 10$ & $1 \%$ & $5 \%$ & $20 \%$ & $0 \%$ & $20 \%$ & $1 \%$ & \\
\hline no response & $19 \%$ & $19 \%$ & $19 \%$ & $19 \%$ & $19 \%$ & $22 \%$ & \\
\hline
\end{tabular}

\section{Use of analgesia}

The two main methods of providing analgesia (NSAIDs and local anaesthesia) were considered separately. Figure 2 shows the proportion of respondents using NSAID in at least $50 \%$ of cases across a range of conditions and procedures, plotted alongside the distribution of pain scores for the same conditions and procedures. Generally, it is clear that the conditions scored as more painful tended to receive NSAID treatment more commonly. However, a number of conditions were associated with a much lower degree of NSAID use, despite being assigned similar pain scores to conditions much more likely to receive NSAID. This was particularly marked for disbudding and surgical castration in calves and dehorning in adult cattle, with only $20-30 \%$ of respondents using NSAID in at least half of the cases they saw, despite all three having median pain scores of 7-8.

Factors associated with NSAID use were explored further in a multivariable multilevel logistic regression model, with the binary outcome of a respondent stating that they used NSAID in at least $50 \%$ of cases for a given condition or procedure. Parameter estimates for this model are shown in Table 3. As with the model for assignment of pain scores, both year of graduation and gender were retained in the model (suggesting that these are additive and independent effects); the odds of NSAID use were significantly higher for respondents graduating after 2000, and lower for male clinicians. The odds of NSAID use were higher where the estimated true cost of NSAID treatment was within the respondent's acceptable range. 
Table 3: Parameter estimates for a logistic regression model with the (binary) outcome representing whether a respondent used NSAID in more than $50 \%$ of cases of a particular condition or procedure in a survey investigating attitudes to pain and use of analgesia in cattle. $95 \% \mathrm{Cl}=95 \%$ Bayesian credible interval.

\begin{tabular}{|l|c|c|}
\hline Model term & $\mathbf{n}$ & Odds ratio (95\% Cl) \\
\hline Format: online & 1442 & reference \\
\hline Format: paper & 1226 & $0.59(0.4-0.89)$ \\
\hline Year of graduation: <1991 & 629 & reference \\
\hline Year of graduation: 1991-2000 & 447 & $1.26(0.74-2.32)$ \\
\hline Year of graduation: 2001-2005 & 376 & $2.01(1.07-3.8)$ \\
\hline Year of graduation: 2006-2010 & 779 & $2.2(1.27-3.81)$ \\
\hline Year of graduation: $>2010$ & 437 & $2.64(1.41-5.07)$ \\
\hline Gender: female & 1208 & reference \\
\hline Gender: male & 1460 & $0.61(0.41-0.91)$ \\
\hline Cost acceptable: no & 584 & reference \\
\hline Cost acceptable: yes & 2023 & $4.52(3.15-6.52)$ \\
\hline Cost acceptable: N/A & 61 & $0.3(0.1-0.9)$ \\
\hline Pain score: <4 & 124 & $0.09(0.03-0.23)$ \\
\hline Pain score: 4 & 139 & $0.79(0.45-1.41)$ \\
\hline Pain score: 5 & 258 & $1.07(0.67-1.7)$ \\
\hline Pain score: 6 & 307 & reference \\
\hline Pain score: 7 & 441 & $2.03(1.29-3.03)$ \\
\hline Pain score: 8 & 504 & $3.1(2.08-4.95)$ \\
\hline Pain score: 9 & 419 & $2.91(1.77-4.64)$ \\
\hline Pain score: 10 & 476 & $2.57(1.51-4.38)$ \\
\hline Condition: dystocia (cow) & 211 & reference \\
\hline Condition: caesarean & 211 & $2.62(1.21-5.99)$ \\
\hline Condition: dystocia (calf) & 199 & $0.06(0.03-0.11)$ \\
\hline Condition: castration & 200 & $0.03(0.02-0.06)$ \\
\hline Condition: digit amputation & 211 & $2.71(1.19-6.07)$ \\
\hline Condition: dehorning (adult) & 211 & $0.08(0.04-0.14)$ \\
\hline Condition: disbudding (calf) & 200 & $0.02(0.01-0.03)$ \\
\hline Condition: hernia surgery & 198 & $1.32(0.66-2.69)$ \\
\hline Condition: joint ill & 199 & $0.98(0.52-1.84)$ \\
\hline Condition: LDA surgery & 209 & $1.12(0.6-2.19)$ \\
\hline Condition: fractured limb (calf) & 200 & $2.37(1.03-5.4)$ \\
\hline Condition: treatment of SU & 210 & $0.49(0.28-0.87)$ \\
\hline Condition: uveitis & 209 & $0.19(0.1-0.32)$ \\
\hline
\end{tabular}

Pain score was also associated with the odds of NSAID use: conditions scored 3 or less were associated with significantly lower odds of use compared to those scored 4, 5 or 6 , which in turn were associated with lower use than conditions scored 7 or higher. Several of the conditions also had significant associations with use of NSAID, even after accounting for the other factors in the model (including the pain score assigned by that respondent to that condition). This was most 
marked for disbudding, castration and dystocia in calves, and dehorning in adult cattle, all of which were associated with much lower levels of NSAID use. This effectively demonstrates that the "decoupling" of pain score from NSAID use across these conditions highlighted in Figure 2 is a statistically significant effect, and that it persists when other potential confounding variables have been accounted for.

The vast majority of respondents used local anaesthesia for all of the surgical procedures. Over $95 \%$ of respondents reported that they used local anaesthesia in all cases for caesarean sections, digit amputation and dehorning adult animals, and between 90 and $95 \%$ of respondents used local anaesthesia for all left displaced abomasum surgery and calf disbudding. Two thirds of respondents (67\%) used local anaesthesia for all calf castration.

\section{Opinions regarding analgesia and pain}

Just under $70 \%$ of respondents (142 of 203) felt that their knowledge of this area was adequate. Two thirds of respondents (138 of 209) stated that their use of analgesia had increased in the last five to ten years. Where use had increased, changes in farmer attitude were cited as the most common reasons for change (mentioned by $77 \%$ of those reporting increased use, $n=106 / 138$ ). Changes in respondent perception of pain in cattle, new scientific evidence and decreasing medicine costs were the next most common reason (59\%, 56\% and $43 \% ; n=82,78$ and 59/138 respectively). Influence of colleagues $(35 \%, n=48 / 138)$ and practice policy $(28 \%, n=38 / 138)$ were less commonly mentioned. Further responses to the questions regarding opinions on analgesia and pain in cattle are summarised in Table 4.

Table 4: Summary of responses to questions regarding survey respondents' opinions around analgesia and pain management in cattle ( $n=199$, respondents not answering these questions excluded).

\begin{tabular}{|l|l|l|l|}
\hline Statement & Agree & Disagree & Not sure \\
\hline $\begin{array}{l}\text { Analgesics may mask deterioration in the animal's } \\
\text { condition }\end{array}$ & $21 \%$ & $58 \%$ & $21 \%$ \\
\hline $\begin{array}{l}\text { Cattle benefit from receiving analgesic drugs as part of } \\
\text { their treatment }\end{array}$ & $99 \%$ & $0 \%$ & $1 \%$ \\
\hline $\begin{array}{l}\text { Some pain is necessary to stop the animal becoming too } \\
\text { active }\end{array}$ & $12 \%$ & $73 \%$ & $15 \%$ \\
\hline Cattle recover faster if given analgesic drugs & $96 \%$ & $0 \%$ & $4 \%$ \\
\hline $\begin{array}{l}\text { Drug side effects limit the usefulness of giving analgesics } \\
\text { to cattle }\end{array}$ & $5 \%$ & $83 \%$ & $12 \%$ \\
\hline $\begin{array}{l}\text { Farmers are happy to pay the costs associated with giving } \\
\text { analgesics to cattle }\end{array}$ & $52 \%$ & $14 \%$ & $34 \%$ \\
\hline $\begin{array}{l}\text { Farmers would like cattle to receive analgesia but cost is } \\
\text { a major issue }\end{array}$ & $45 \%$ & $33 \%$ & $23 \%$ \\
\hline $\begin{array}{l}\text { E.U. legislation limits my ability to use analgesic drugs in } \\
\text { cattle }\end{array}$ & $29 \%$ & $56 \%$ & $15 \%$ \\
\hline
\end{tabular}

\section{DISCUSSION}

The results of the current study suggest that perception of pain in cattle by cattle practitioners has increased since the work of Huxley and Whay (2006), with over $40 \%$ of the procedures and conditions listed being given a higher median pain severity score. Despite the trend for increasing 
pain severity scores there is still a large degree of variation between practitioners. Some of this variation is explained by the gender of the participant, with male practitioners on average giving lower pain severity scores than female practitioners. This is consistent with previous findings in the UK (Huxley and Whay 2006), from overseas (Becker and others 2013; Kielland and others 2009; Lorena and others 2013) and in small animal practice (Williams and others 2005). Year of graduation also had a significant association with pain score, with respondents graduating before 1990 giving significantly lower pain scores than those graduating after 2010. This is also consistent with the previous findings (Huxley and Whay 2006) and findings outside the UK (Becker and others 2013; Raekallio and others 2003). This is one of the first studies in this area to use a multivariable technique to confirm that the associations with gender and year of graduation exist independently and are not confounded by the changing gender balance of veterinary graduates over time. This may reflect advances in our understanding of pain and pain management as well as increased importance placed on pain recognition and management in undergraduate veterinary curricula. Variables that initially appeared to be associated with pain scores, such as school of graduation, pre-university background and post-graduate qualifications were not retained in the multivariable model suggesting that the apparent associations initially identified were confounded by correlations with gender and year of graduation. Other factors not measured here, such as empathy of the respondents, have also been shown to affect participants' perception of pain in cattle, although empathy is also associated with gender and pain perception tends to be strongly correlated with empathy (Norring and others 2014). The apparent increased perception of pain by more recent graduates is encouraging and suggests that things are changing, however another possible explanation is that veterinary surgeons' sensitivity to signs of pain declines with experience. It has been shown that experienced human acupuncturists' brains react differently to control groups when viewing videos of needles been pushed in to patients (Cheng and others 2007).

As with previous studies, the perception of pain severity by respondents broadly correlated with an increased willingness to administer analgesics (Huxley and Whay 2006; Laven and others 2009). Therefore, an increased ability to recognise and identify pain in cattle is likely to result in increased administration of analgesics to animals in pain or animals undergoing painful procedures. This is supported by the majority of respondents stating that their use of analgesia had increased over the previous 5-10 years. Although these results are broadly positive, a potential area of concern was the apparent decoupling of analgesic use from perceived pain severity in routine calf procedures. Calves undergoing painful husbandry procedures such as disbudding and castration were significantly less likely to receive NSAID treatment despite these procedures receiving a pain severity score similar to other conditions and procedures in adult cattle. These findings suggest that in these animals the main barrier to administration of analgesic medicines by veterinary surgeons is no longer the ability to identify or recognise pain (Huxley and Whay 2006). Both disbudding and castration have been shown to be painful to calves (Fisher and others 1996; Graf and Senn 1999). Whilst most (although not all) respondents reported using local anaesthesia when castrating and disbudding calves, the addition of a NSAID to the protocol has been shown to further control the pain associated with these procedures, particularly the post-operative pain as the local anaesthetic wanes (Coetzee 2011; Heinrich and others 2010; Heinrich and others 2009; Stafford and Mellor 2011). The use of NSAID (ideally pre-emptively) in addition to local anaesthetic for both disbudding and castration of calves is considered best practice and this approach has been described in numerous reviews and continuing education journals (Coetzee 2013; Hudson and others 2008; Stock and others 2013). It is worth highlighting that legislation in this area is often dated (e.g. over 50 years old in the UK) and can be slow and difficult to change. Legislation may lag behind scientific understanding, societal opinion and available pharmaceuticals. At times, legislation can be used to defend and legitimise protocols which 
many would find outdated and even unacceptable. Industry led initiatives and codes of practice provide an opportunity to encourage best practice and respond to developments in a more dynamic way (Anon 2016).

As the existing barriers to NSAID use are reduced it is important that new barriers are not created. Informal feedback from producers suggests that there may be two challenges with terminology in this area (at least in English - the same may not be true in other languages). Firstly "NSAIDs", "nonsteroidals" and "anti-inflammatories" are more medical terms which can confuse producers and complicate the message. "Pain killer" is a more widely understood and user friendly term accepting that it is imprecise and doesn't acknowledge the other important pharmacological actions of this group of drugs. Secondly the drive to rationalise antibiotic administration in food animals, because of the concerns over antimicrobial resistance, appears to be leading to fear and confusion amongst some producers over all injectable products. This is particularly the case for NSAIDs because of the incorrectly perceived similarities/associations between "anti-biotics" and "anti-inflammatories". It is imperative that the drive to reduce, refine and replace antibiotic usage does not lead to a reduction in anti-inflammatory administration. It is also important to ensure that public perception of the use of NSAIDs and other analgesics is considered and that the benefits of analgesics are effectively communicated to all stakeholders in the supply chain.

If recognition, perception and awareness of pain is becoming less of a barrier to the use of NSAIDs then there is a need to explore further barriers. Cost is often identified as a barrier to analgesic use, in the earlier work of Whay and Huxley (2005) over $65 \%$ of respondents agreed that "farmers would like cattle to receive analgesia but cost is a major issue"; in the current study this has reduced to $45 \%$. Similarly, the percentage of respondents agreeing that "farmers are happy to pay the costs involved with giving analgesics to cattle" has increased from $36 \%$ to $52 \%$ between the two studies. This suggests that, whilst cost is still an issue, attitudes in this area are changing. In this study, procedures such as disbudding and castrating calves were allocated the lowest acceptable costs of analgesia by respondents. However, the estimated cost of providing NSAID analgesia for these procedures were still within the acceptable range given for disbudding for over $90 \%$ of respondents. This is a positive sign and may reflect the decreasing price and increasing availability of NSAIDs licensed for use in cattle in the UK. Interestingly, in a study of Danish veterinarians and dairy farmers, whilst less farmers than veterinarians agreed that using analgesics makes economic sense (64\% and $85.1 \%$ respectively) only a minority of both groups ( $27 \%$ and $26.1 \%$ ) agreed that they would like to use analgesics for cows but that price was a major problem (Thomsen and others 2012). This suggests that although they may not see a cost-benefit, farmers are still willing to use analgesia in their animals. Winder and others (2016) showed that veterinarians were far more likely than producers to cite cost as a reason not to use NSAIDs for disbudding. This is similar to findings relating to the control of mastitis where non-monetary factors such as taking pride in healthy animals were equally important as economic drivers (Valeeva and others 2007).

The response rate to the paper questionnaire was $16 \%$, lower than that reported in the original study by Huxley and Whay (2006). However, an electronic version of the questionnaire was also created in this study and signposted in the paper copy. Whilst care needs to be taken in generalising the results from this survey, there was a wide distribution of years since graduation and an increased proportion of female respondents compared to the previous study. This may reflect changing demographics within the profession. The multivariable regression models used in the analysis should account for any effect of the increased proportion of female respondents. Whilst eliminating bias completely is difficult, it might be expected that veterinary surgeons with an interest in analgesia and animal welfare might be more inclined to complete the survey and also to use analgesics. 
Similarly there is risk of respondent answering in line with expectations. Both these potential biases would likely result in an overestimation of analgesic use.

\section{CONCLUSION}

Over the last decade, there has been a promising increase in the use of analgesics by UK veterinary surgeons treating painful conditions or carrying out painful procedures in cattle. This corresponds to an associated increased in the pain severity scores given for many of these procedures. There is a concerning mismatch between frequency of analgesic use (at least in terms of NSAID) and perceived severity of pain in routine calf procedures such as disbudding and castration, an area which clearly warrants further work.

\section{ACKNOWLEDGEMENTS}

The authors would like to acknowledge the financial support of Boehringer Ingelheim for the printing and distribution of the paper questionnaires. The time and support of all the clinicians who completed the survey is also gratefully acknowledged.

\section{REFERENCES}

ANON (2016) Industry 'disappointed' as Defra backtracks on welfare codes. Veterinary Record 178, 383-383

BECKER, J., REIST, M., FRIEDLI, K., STRABEL, D., WÜTHRICH, M. \& STEINER, A. (2013) Current attitudes of bovine practitioners, clawtrimmers and farmers in Switzerland to pain and painful interventions in the feet in dairy cattle. The veterinary journal 196, 467-476 CHENG, Y., LIN, C.-P., LIU, H.-L., HSU, Y.-Y., LIM, K.-E., HUNG, D. \& DECETY, J. (2007) Expertise Modulates the Perception of Pain in Others. Current Biology 17, 1708-1713

COETZEE, J. F. (2011) A review of pain assessment techniques and pharmacological approaches to pain relief after bovine castration: Practical implications for cattle production within the United States. Applied Animal Behaviour Science 135, 192-213 COETZEE, J. F. (2013) Assessment and Management of Pain Associated with Castration in Cattle. Veterinary Clinics of North America: Food Animal Practice 29, 75-101 FISHER, A., CROWE, M., ALONSO DE LA VARGA, M. \& ENRIGHT, W. (1996) Effect of castration method and the provision of local anesthesia on plasma cortisol, scrotal circumference, growth, and feed intake of bull calves. Journal of Animal Science 74, 2336-2343 FITZPATRICK, C. E., CHAPINAL, N., PETERSSON-WOLFE, C. S., DEVRIES, T. J., KELTON, D. F., DUFFIELD, T. F. \& LESLIE, K. E. (2013) The effect of 
meloxicam on pain sensitivity, rumination time, and clinical signs in dairy cows with endotoxin-induced clinical mastitis. Journal of dairy science 96, 2847-2856

FITZPATRICK, J. L., YOUNG, F. J., ECKERSALL, D., LOGUE, D., KNIGHT, C. \& NOLAN, A. (1998) Recognising and controlling pain and inflammation in mastitis. In Proc of the British Mastitis Conference. pp 36-44

GRAF, B. \& SENN, M. (1999) Behavioural and physiological responses of calves to dehorning by heat cauterization with or without local anaesthesia. Applied Animal Behaviour Science 62, 153-171 HEINRICH, A., DUFFIELD, T. F., LISSEMORE, K. D. \& MILLMAN, S. T. (2010) The effect of meloxicam on behavior and pain sensitivity of dairy calves following cautery dehorning with a local anesthetic. Journal of dairy science 93, 2450-2457

HEINRICH, A., DUFFIELD, T. F., LISSEMORE, K. D., SQUIRES, E. J. \& MILLMAN, S. T. (2009) The impact of meloxicam on postsurgical stress associated with cautery dehorning. Journal of dairy science $92,540-$ 547

HUDSON, C., WHAY, H. \& HUXLEY, J. (2008) Recognition and management of pain in cattle. In Practice 30, 126-134 HUXLEY, J. N. \& WHAY, H. R. (2006) Current attitudes of cattle practitioners to pain and the use of analgesics in cattle. Veterinary Record 159, 662-668

KIELLAND, C., SKJERVE, E. \& ZANELLA, A. J. (2009) Attitudes of veterinary students to pain in cattle. Veterinary Record 165, 254-258 LAVEN, R. A., HUXLEY, J. N., WHAY, H. R. \& STAFFORD, K. J. (2009) Results of a survey of attitudes of dairy veterinarians in New Zealand regarding painful procedures and conditions in cattle. New Zealand Veterinary Journal 57, 215-220

LORENA, S. E., LUNA, S. P., LASCELLES, B. D. X. \& CORRENTE, J. E. (2013) Attitude of Brazilian veterinarians in the recognition and treatment of pain in horses and cattle. Veterinary anaesthesia and analgesia 40, 410-418 
NORRING, M., WIKMAN, I., HOKKANEN, A.-H., KUJALA, M. V. \& HÄNNINEN, L. (2014) Empathic veterinarians score cattle pain higher. The veterinary journal 200, 186-190 POHL, A., BERTULAT, S., BORCHARDT, S., BURFEIND, O. \& HEUWIESER, W. (2016) Randomized, controlled clinical trial on the efficacy of nonsteroidal antiinflammatory drugs for the treatment of acute puerperal metritis in dairy cows. Journal of dairy science 99, 8241-8249

R CORE TEAM (2013) R: A language and environment for statistical computing. Vienna, Austria, R Foundation for Statistical Computing RAEKALLIO, M., HEINONEN, K., KUUSSAARI, J. \& VAINIO, O. (2003) Pain alleviation in animals: attitudes and practices of Finnish veterinarians. The veterinary journal 165, 131-135 RASBASH, J., CHARLTON, C., BROWNE, W. J., HEALY, M. \& CAMERON, B. (2009) MLwiN Version 2.1. Centre for Multilevel Modelling, University of Bristol, Bristol, UK ROBERTSON, I., KENT, J. \& MOLONY, V. (1994) Effect of different methods of castration on behaviour and plasma cortisol in calves of three ages. Research in Veterinary Science 56, 8-17 STAFFORD, K. J. \& MELLOR, D. J. (2011) Addressing the pain associated with disbudding and dehorning in cattle. Applied Animal Behaviour Science 135, 226-231

STAFFORD, K. J., MELLOR, D. J., TODD, S. E., BRUCE, R. A. \& WARD, R. N. (2002) Effects of local anaesthesia or local anaesthesia plus a nonsteroidal anti-inflammatory drug on the acute cortisol response of calves to five different methods of castration. Research in Veterinary Science 73, 61-70

STOCK, M. L., BALDRIDGE, S. L., GRIFFIN, D. \& COETZEE, J. F. (2013) Bovine Dehorning: Assessing Pain and Providing Analgesic Management. Veterinary Clinics of North America: Food Animal Practice 29, 103-133

THOMAS, H., MIGUEL-PACHECO, G., BOLLARD, N., ARCHER, S., BELL, N., MASON, C., MAXWELL, O., REMNANT, J., SLEEMAN, P. \& WHAY, $\mathrm{H}$. (2015) Evaluation of treatments for claw horn lesions in dairy cows 
in a randomized controlled trial. Journal of dairy science $98,4477-$ 4486

THOMSEN, P. T., ANNEBERG, I. \& HERSKIN, M. S. (2012) Differences in attitudes of farmers and veterinarians towards pain in dairy cows. The veterinary journal 194, 94-97

VALEEVA, N. I., LAM, T. J. G. M. \& HOGEVEEN, H. (2007) Motivation of Dairy Farmers to Improve Mastitis Management. Journal of dairy science 90, 4466-4477

WALKER, K. A., DUFFIELD, T. F. \& WEARY, D. M. (2011) Identifying and preventing pain during and after surgery in farm animals. Applied Animal Behaviour Science 135, 259-265

WHAY, H., WATERMAN, A. \& WEBSTER, A. (1997) Associations between locomotion, claw lesions andnociceptive threshold in dairy heifers during the peri-partum period. The veterinary journal 154, 155-161

WHAY, H. R. \& HUXLEY, J. N. (2005) Pain Relief in Cattle: A Practitioners Perspective. Cattle Practice 13, 81-85 WILLIAMS, V. M., LASCELLES, B. D. \& ROBSON, M. C. (2005) Current attitudes to, and use of, peri-operative analgesia in dogs and cats by veterinarians in New Zealand. N Z Vet J 53, 193-202 WINDER, C. B., LEBLANC, S. J., HALEY, D. B., LISSEMORE, K. D., GODKIN, M. A. \& DUFFIELD, T. F. (2016) Practices for the disbudding and dehorning of dairy calves by veterinarians and dairy producers in Ontario, Canada. Journal of dairy science 99, 10161-10173 


\section{Figure legends}

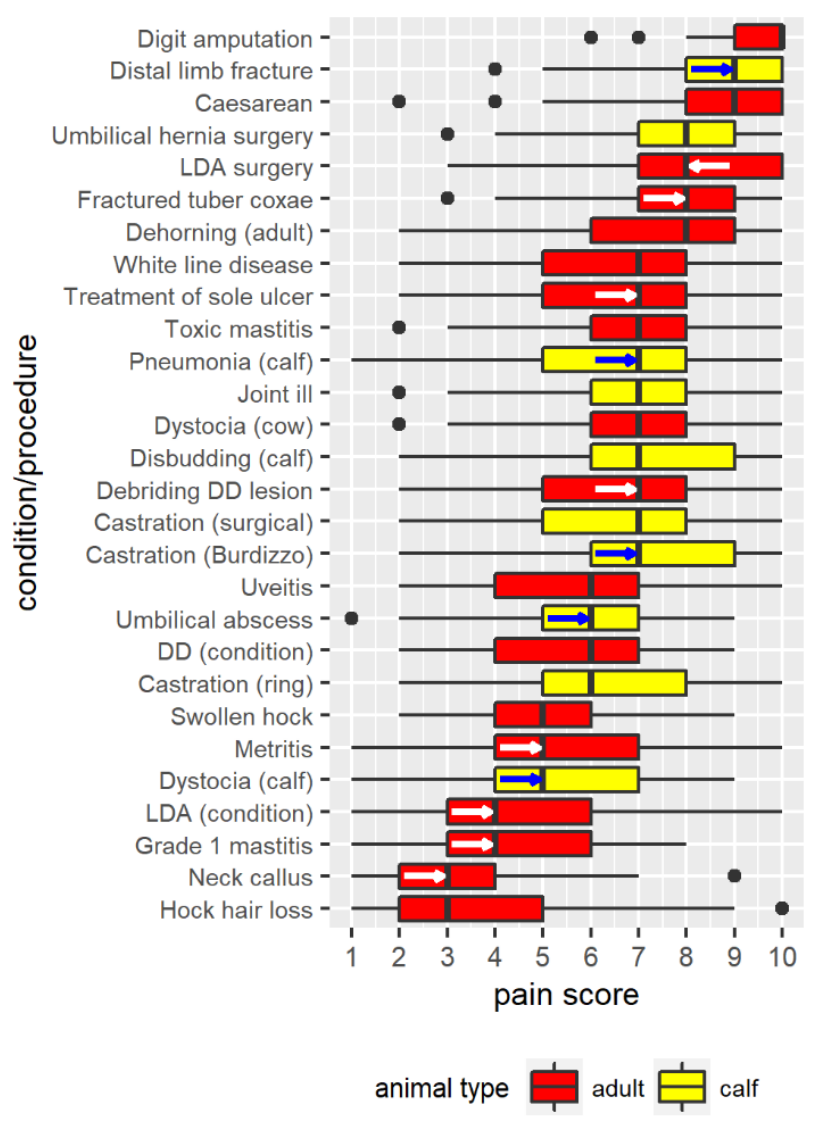

Figure 1: Distribution of pain scores (where 1 represents no pain and 10 the worst pain imaginable) assigned to various conditions and procedures. Boxes show the interquartile range (IQR) of scores for each condition, vertical black lines the median score and horizontal lines the range (where any scores lie outside the IQR by more than 1.5 times the size of the IQR, they are represented by points beyond the line). The colour of the IQR box denotes animal type (adult versus calf), and arrows show change in median score compared to a 2004 survey using the same questions (Huxley and Whay 2006), with the non-head-end of the arrow showing the 2004 median.

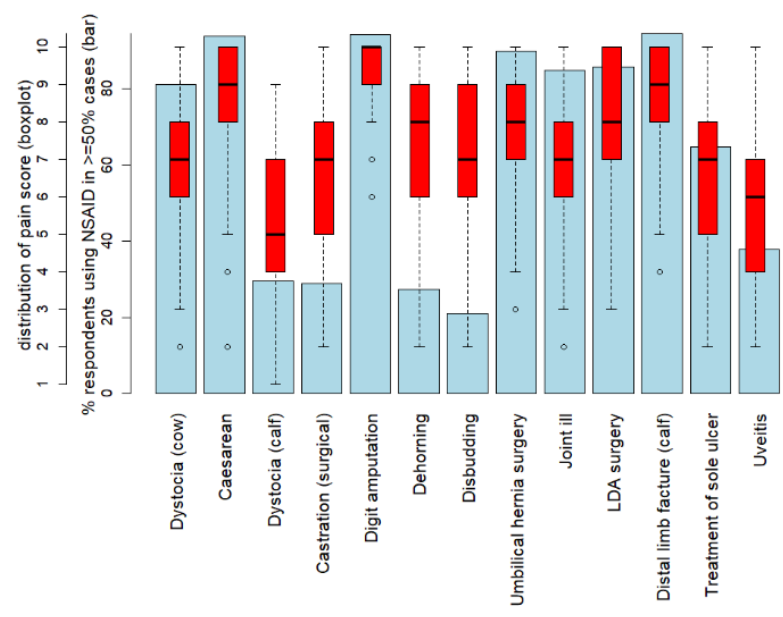

Figure 2: Proportion of respondents using NSAID treatment in more than $50 \%$ of cases across a range of conditions and procedures (blue bars, inner vertical scale). Distribution of pain scores 
assigned to the same conditions and procedures is also shown (red boxplots, outer vertical scale). Boxes show the interquartile range (IQR) of scores for each condition, horizontal black lines the median score and vertical lines the range (where any scores lie outside the IQR by more than 1.5 times the size of the IQR, they are represented by points beyond the line). 